\title{
Improvement of the performance stability of power grid with wind farms using static synchronous compensator
}

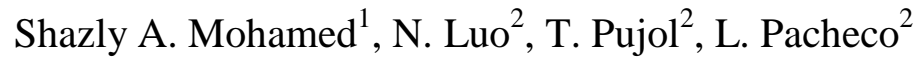 \\ ${ }^{1}$ Department of Electrical Engineering, Faculty of Engineering, South Valley University, Qena, Egypt. \\ ${ }^{2}$ Polytechnic School, University of Girona, Campus Montilivi, 17071 Girona, Spain. \\ Corresponding author: N. Luo, phone number: +0034 656475276, e-mail: ningsu.luo@udg.edu
}

\begin{abstract}
The technological advancements in wind energy conversion have led to increased wind power generation in recent years. Static synchronous compensator (STATCOM) is used extensively in power systems due to its ability of providing the flexible power flow control. The main motivation for choosing STATCOM in wind farms is that it can provide bus bar system voltage support either by supplying or absorbing reactive power into the system, thereby can improve the steadystate stability limits of the network. This paper deals with the impact of STATCOM on the wind farm performance. The wind turbines considered are fixed speed ones with squirrel cage induction generator. In this work the performance of wind farm with and without STATCOM is investigated under fault conditions.
\end{abstract}

\section{Keywords}

Wind farm, power grid, power system stability, FACTS devices, STATCOM.

\section{Introduction}

The main benefit of reactive power compensation in an electrical system is the voltage regulation, increased system stability, better utilization of machines connected to the system, reduction of losses associated with the system, prevention of the voltage collapse and voltage sag. The impedance of transmission lines and the need for lagging VAR machines in a generating system result in the consumption of reactive power, which affect the stability limits of the system as well as transmission lines [1]. Unnecessary voltage drops will lead to increased losses that need to be supplied by the source and in turn lead to outages in the line due to increased stress on the system to carry this imaginary power. Thus, the compensation of reactive power can not only mitigate all these effects but also help in better transient response to faults and disturbances. It is srongtly required that the lines be relieved of the obligation to carry the reactive power, which is better provided near the generators or the loads. Shunt compensation can be installed near the load, in a distribution substation or transmission substation [2].
In recent years there has been an increased focus on the techniques used for the compensation. FACTS are the acronym for Flexible Alternating Current Transmission Systems incorporating power-electronics based and other static controllers to enhance controllability and power transfer capability. The main purpose of FACTS is to supply the network as quickly as possible with inductive or capacitive reactive power that is adapted to its particular requirements, while improving the quality and efficiency of power transmission systems. STATCOM is a voltage-source inverter (VSI), which converts a DC input voltage into $\mathrm{AC}$ output voltage in order to compensate the active and reactive power needed by the system [3-5]. Also, STATCOM is added to the power network to provide dynamic voltage control for the wind farm, to make the dynamic power flow control for the transmission lines, to relieve transmission congestion and to improve power oscillation damping [6-10].

In this study the performance of a wind farm with and without STATCOM is investigated. We present a simple and efficient model for a $9 \mathrm{MW}$ wind farm that consists of wind turbine, induction generator, STATCOM and bus. This model describes the dynamic behavior of bus voltage. Simulation is carried out by using MATLAB/ Simulink program package to verify the validity of the proposed model. The paper is structured as follows. Section 2 presents the system, characteristics, working principle and control structure of the STATCOM. Section 3 describes the studied system and wind farm model. In Section 4, simulation results and discussions for STATCOM response are presented. Finally, main conclusions are illustrated in section 5 .

\section{STATCOM}

STATCOM is a VSI, which converts DC input voltage into AC output voltage in order to compensate the active and reactive power needed by the system. STATCOM can be considered as an advanced static VAR compensator in which a voltage source converter (VSC) 
is used instead of the controllable reactors and switched capacitors [11]. The STATCOM is a shunt-connected device of FACTS family using power electronics to control power flow and improve transient stability on power grid. The STATCOM regulates voltage at its terminal by controlling the amount of reactive power injected into or absorbed from the power system. When the system voltage is low, the STATCOM generates reactive power (STATCOM capacitive) and when the system voltage is high, it absorbs reactive power (STATCOM inductive).

\section{A. System of STATCOM}

The system circuit consists of a DC energy storage device (capacitor), a VSC for generating a controllable AC voltage source behind the transformer reactance, the voltage difference across the reactance of the transformer produces active and reactive power exchange between STATCOM and the power system. The STATCOM output voltage magnitude can be adjusted by controlling the voltage across the DC capacitor. The STATCOM in wind farm is usually located at the entrance of the grid. For small rated STATCOM, it is preferable to locate it at each wind turbine [12]. Figure 1 shows the schematic of the STATCOM.

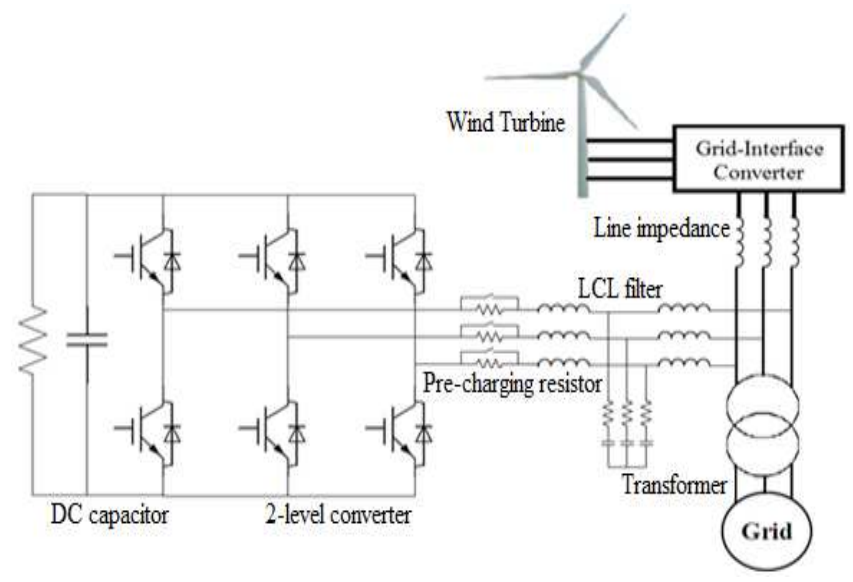

Fig. 1: Schematic of the STATCOM

\section{B. V-I characteristic of STATCOM}

The STATCOM can supply both the capacitive and the inductive compensation and is able to independently control its output current over the rated maximum capacitive or inductive range irrespective of the amount of AC-system voltage. The STATCOM is necessary to support the system voltage during and after faults which otherwise will cause voltage collapse. When the STATCOM is worked in voltage regulation mode, it implements the V-I characteristics as shown in Fig. 2. The V-I characteristics is described by the following equation:

$$
V=V_{r e f}+X_{s} I
$$

where $V$ is the positive sequence voltage, $I$ is the reactive current $(I>0$ indicates an inductive current and $I<0$ indicates capacitive current), and $X_{S}$ is the drop reactance (usually between $1 \%$ and $5 \%$ ).

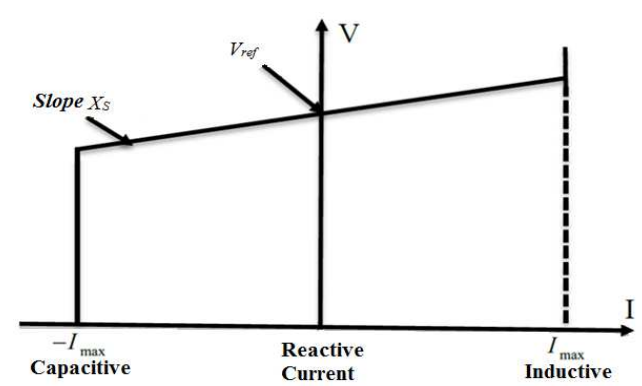

Fig. 2: Typical steady state V-I characteristic of a STATCOM

\section{Working Principle of STATCOM:}

STATCOM is a controlled reactive-power source. It provides the desired reactive-power generation and absorption entirely by means of electronic processing of the voltage and current waveforms in a VSC. A STATCOM principle diagram is shown in Fig. 3, which is seen as an adjustable voltage source behind a reactance. It means that the capacitor banks and shunt reactors are not needed for reactive-power generation and absorption, thereby it gives the STATCOM a compact design. The coupling transformer plays two different roles. First, it connects the converter to the high voltage power system. Secondly, the transformer inductance ensures that DC capacitor is not short-circuited and discharged rapidly [13-14].
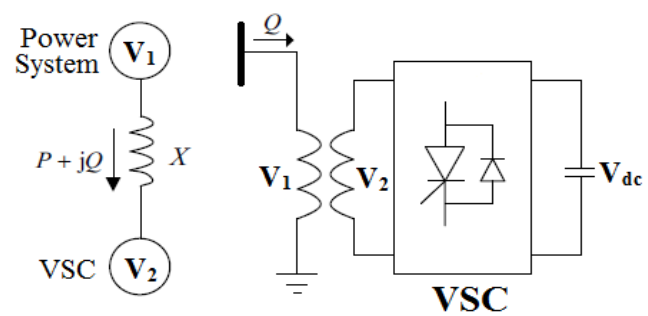

Fig. 3: Diagram of STATCOM working principle

$V_{l}$ is the bus terminal voltage, $V_{2}$ is the output voltage of STATCOM, $V_{d c}$ is the DC capacitor side voltage, $X_{L}$ is the inductive reactance, and $\delta$ is the phase angle of $V_{l}$ with respect to $V_{2}$.

General mathematical equation of STATCOM for active or real power, reactive power and STATCOM output voltage can be expressed as follows:

$$
\begin{gathered}
P=\left(V_{1} \cdot V_{2}\right) \sin \delta / X_{L} \\
Q=V_{1} \cdot\left(V_{1}-V_{2} \cos \delta\right) / X_{L}
\end{gathered}
$$

The relationship between fundamental component of the converter AC output voltage and voltage across DC capacitor is given as:

$$
V_{o u t}=K \cdot V_{d c}
$$

where $K$ is coefficient which depends upon on the converter configuration, number of switching pulses and the converter controls.

The following operation modes of STATCOM are given:

1- Normal excited mode of operation $\left(V_{2}=V_{l}\right)$ :

If the output voltage is equal to the $\mathrm{AC}$ system voltage, then the reactive power exchange is zero. 


\section{2- Over exited mode of operation $\left(V_{2} \geq V_{l}\right)$ :}

If the amplitude of the output voltage is increased above that of the AC system voltage, then the current flows through the reactance from the STATCOM to the AC system and the STATCOM generates reactive (capacitive) power for the AC system.

3- Under exited mode of operation $\left(V_{2} \leq V_{1}\right)$ :

If the amplitude of the output voltage is decreased below that of the AC system, then the reactive current flows from the AC system to STATCOM, and the STATCOM absorbs the reactive (inductive) power for the AC system.

\section{STATCOM Control Structure:}

As shown in Fig. 4, the control system consists of phaselocked loop (PLL) which synchronizes on the positivesequence components of the three-phase primary voltage $V_{l}$. The output of the PLL (angle $\theta=\omega t$ ) is used to compute the direct-axis and quadrature-axis components of the AC three-phase voltage and currents (labeled as $V_{\mathrm{d}}$ and $V_{q}$ or $I_{d}$ and $I_{q}$ on the diagram). The $d$ and $q$ components of AC positive-sequence voltage and currents to be controlled as well as the DC voltage $V_{d c}$ are measured. An outer regulation loop consists of an AC voltage regulator and a DC voltage regulator. The output of the AC voltage regulator is the reference current $I_{\text {qref }}$ for the current regulator $\left(I_{q}=\right.$ current in quadrature with voltage which controls reactive power flow). The output of the DC voltage regulator is the reference current $I_{\text {dref }}$ for the current regulator $\left(I_{d}=\right.$ current in phase with voltage which controls active power flow). An inner current regulation loop consists of a current regulator. The current regulator controls the magnitude and phase of the voltage generated by the PWM converter $\left(V_{2 d}, V_{2 q}\right)$ from the $I_{d r e f}$ and $I_{\text {qref }}$ reference currents produced respectively by the $\mathrm{DC}$ and $\mathrm{AC}$ voltage regulators (in voltage control mode). The current regulator is assisted by a feed forward type regulator which predicts the $V_{2}$ voltage output $\left(V_{2 d}, V_{2 q}\right)$ from the $V_{l}$ measurements $\left(V_{l d}\right.$, $V_{l q}$ ) and the transformer leakage reactance.

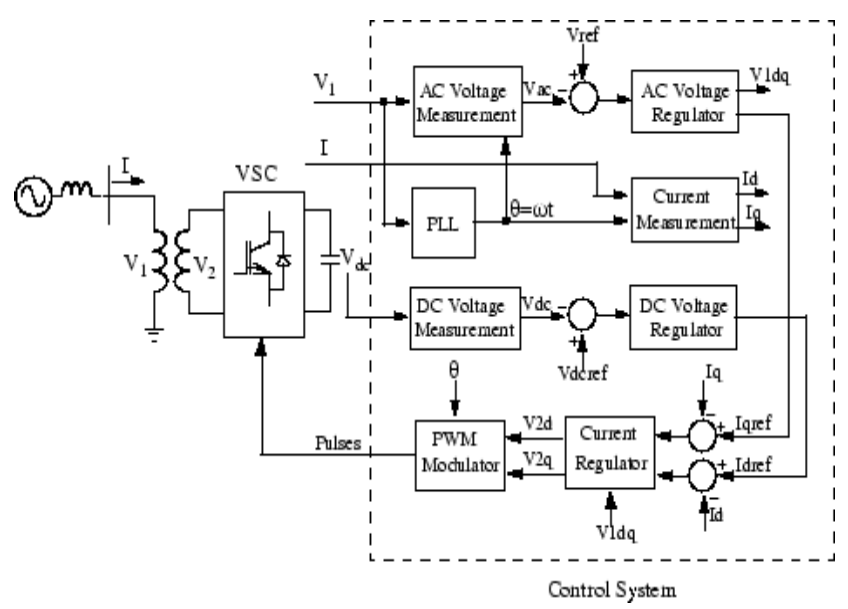

Fig. 4: Single-line diagram of STATCOM and control system block diagram

\section{Wind Farm Model}

A wind farm consisting of six 1.5 MW wind turbines is connected to a $25 \mathrm{kV}$ distribution system and exports power to a $120 \mathrm{kV}$ grid through a $25 \mathrm{kM} 25 \mathrm{kV}$ feeder in the single line diagram of test system as shown in Fig. 5.

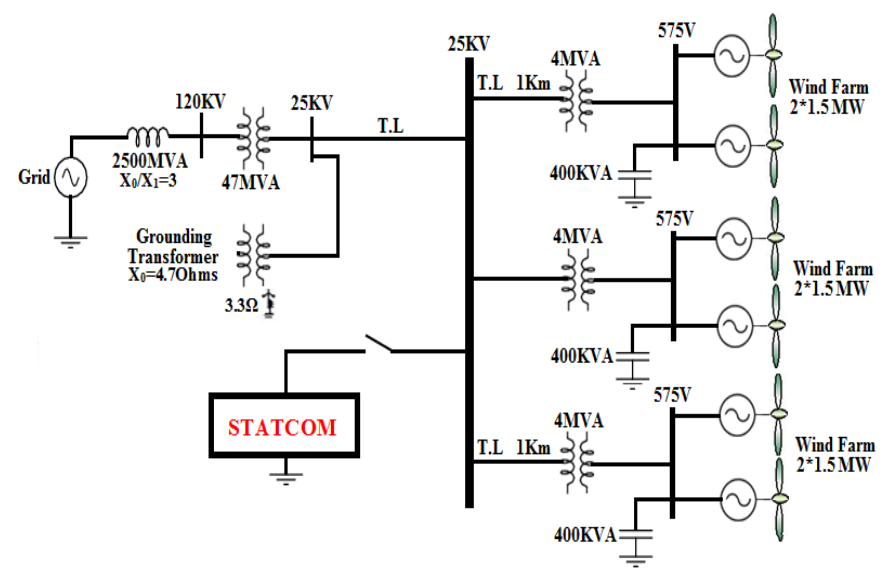

Fig. 5: Single line diagram of test system

With Matlab/Simulink program, an electrical network with asynchronous generator, voltage source, various loads and a $9 \mathrm{MW}$ wind farm which has a 3 MVA STATCOM has been modeled (Simulink diagrama is omitted due to space limitation). The $9 \mathrm{MW}$ wind farm is simulated by three pairs of $1.5 \mathrm{MW}$ wind-turbines. Each wind turbine has a protection system monitoring voltage, current and machine speed. Wind turbines use squirrelcage IG (induction generators). The stator winding is connected directly to the $60 \mathrm{~Hz}$ grid and the rotor is driven by a variable-pitch wind turbine. The pitch angle is controlled to limit the generator output power at its nominal value for winds exceeding the nominal speed (9 $\mathrm{m} / \mathrm{s}$ ). In order to generate power, the IG speed must be slightly above the synchronous speed. Speed varies approximately between $1 \mathrm{pu}$ at no load and $1.005 \mathrm{pu}$ at full load. Reactive power absorbed by IGs is partly compensated by capacitor banks connected at each wind turbine low voltage bus (400 kvar for each pair of 1.5 MW turbines). The rest of reactive power required to maintain the $25 \mathrm{KV}$ voltage at bus B25 close to $1 \mathrm{pu}$ is provided by a 3 MVar STATCOM with $3 \%$ drop setting.

The pitch angle controller regulates the wind turbine blade pitch angle according to the wind speed variations. A Proportional-Integral (PI) controller is used to control the blade pitch angle in order to limit the electric output power to the nominal mechanical power. The pitch angle is kept constant at zero degree when the measured electric output power is under its nominal value. When it increases above its nominal value the PI controller increases the pitch angle to bring back the measured power to its nominal value. The pitch angle control system is illustrated in Fig. 6.

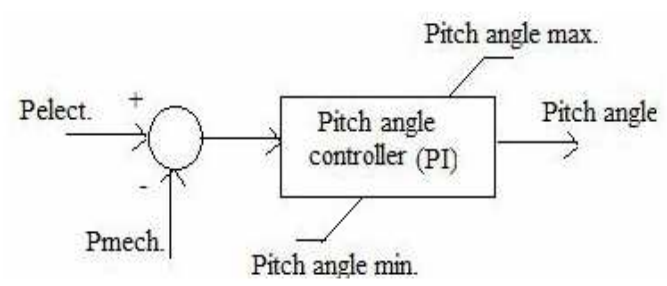

Fig. 6: Control System for pitch angle control 


\section{Simulation Results}

\section{STATCOM responses}

In this study there are three pairs of wind turbines 3.33 MVA in the wind farm, for which we analyze two scenarios: without and with the use of STATCOM in power network. Three-phase fault has been considered that starts at $\mathrm{t}=15 \mathrm{sec}$ and finishes at $\mathrm{t}=15.1 \mathrm{sec}$. Figs. 710 show the simulation results for the response of the wind turbine and the bus-25, for the system cases without and with the STATCOM, respectively. Active power, reactive power, wind turbine speed and voltage on $25 \mathrm{kV}$ bus with and without STATCOM will be analyzed.

\section{Case A. Without STATCOM}

Figure 7 shows the response of active and reactive power, generator speed, wind speed and pitch angle for each turbine on wind turbine scope under three phase fault. For each pair of turbine, the generated active power starts increasing smoothly (together with the wind speed) to reach its rated value of $3 \mathrm{MW}$ in approximately $8 \mathrm{~s}$. Over that time frame the turbine speed is increased from $1.0028 \mathrm{pu}$ to $1.0047 \mathrm{pu}$. Initially, the pitch angle of the turbine blades is zero degree. When the output power exceeds $3 \mathrm{MW}$, the pitch angle is increased from 0 deg to $8 \mathrm{deg}$ in order to bring output power back to its nominal value. It is observed that the absorbed reactive power increases as the generated active power increases. At nominal power, each pair of wind turbine absorbs 1.47 Mvar for an $11 \mathrm{~m} / \mathrm{s}$ wind speed.
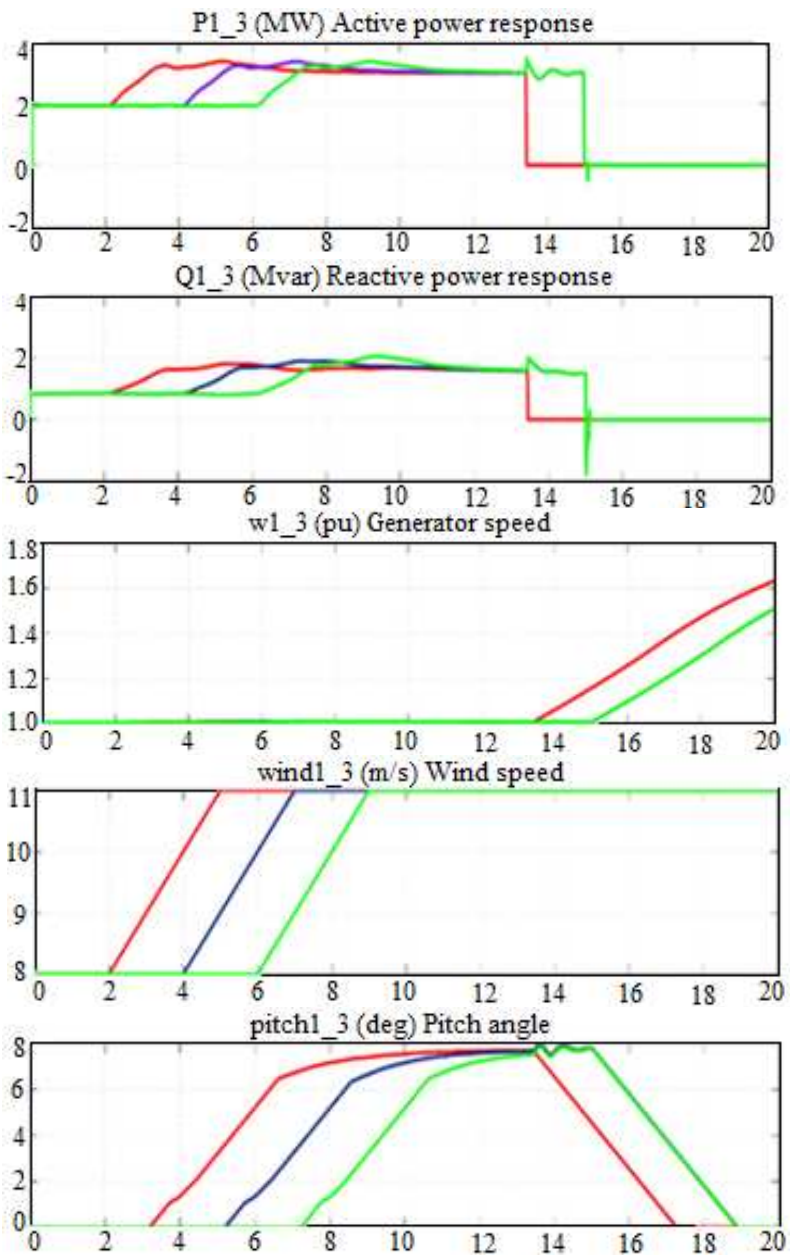

Fig. 7: Response of active, reactive power, generator speed, wind speed and pitch angle on wind turbine scope without STATCOM.

Figure 8 shows the response of voltages, current, active and reactive power on the bus scope under three phase fault. The total exported power measured at the B-25 bus is $9 \mathrm{MW}$ and the STATCOM maintains voltage at 0.984 pu by generating 1.62 Mvar.
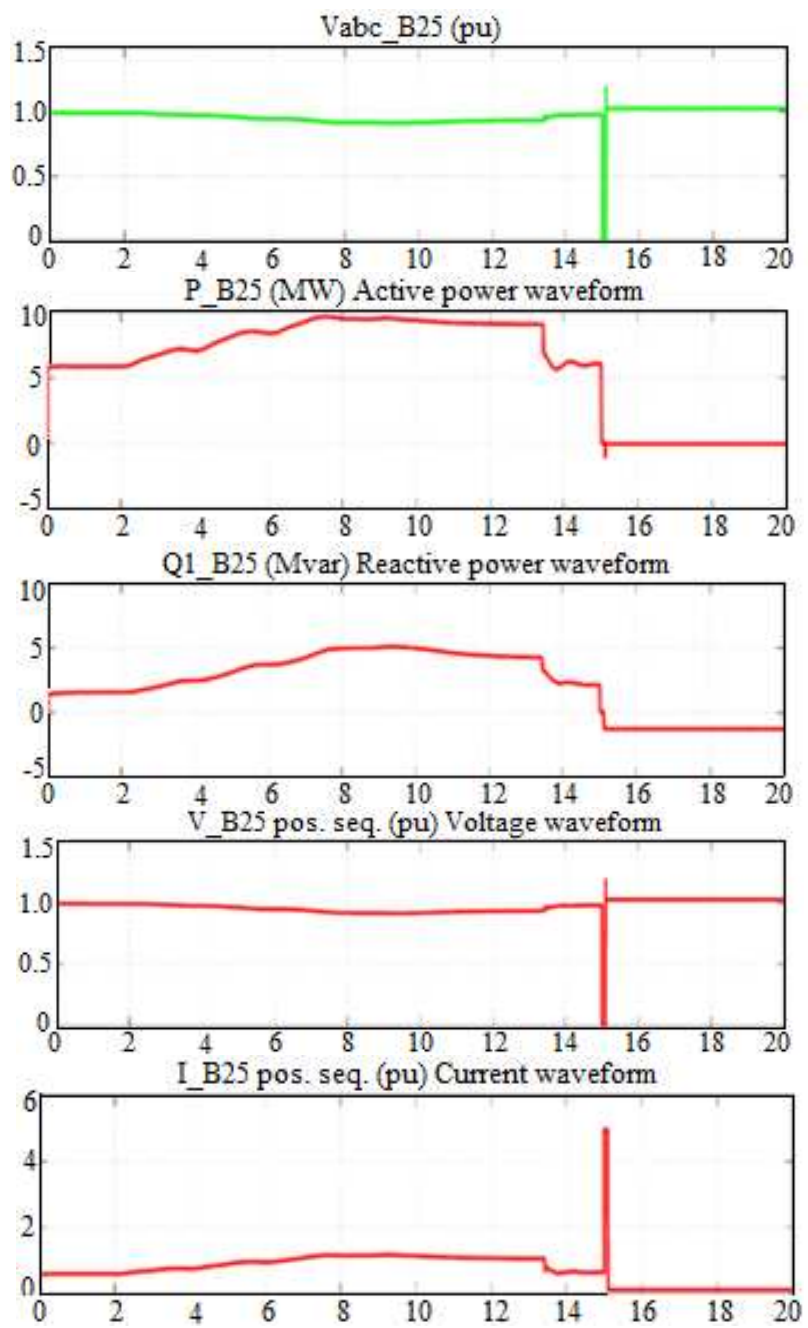

Fig. 8: Response of voltages, current, active and reactive power on the bus scope without STATCOM.

\section{Case B. With STATCOM}

We will now observe the impact of the STATCOM. If the STATCOM is put out of service we can observe that "B25" now drops to $0.91 \mathrm{pu}$ due to the lack of reactive power support. This low voltage condition results in an overload of the IG of "Wind Turbine 1". To avoid this problem STATCOM is used as a better option for the reactive power compensation. Figures 9-10 show the response impact of the STATCOM under three-phase fault. From the simulated model it is observed that the STATCOM stabilizes the system voltage near to the rated value $(1 \mathrm{pu})$ when generated electricity from wind turbine is fed into the system. Moreover, the STATCOM responds to system imbalance within short time and stabilizes the system voltage to rated value. 

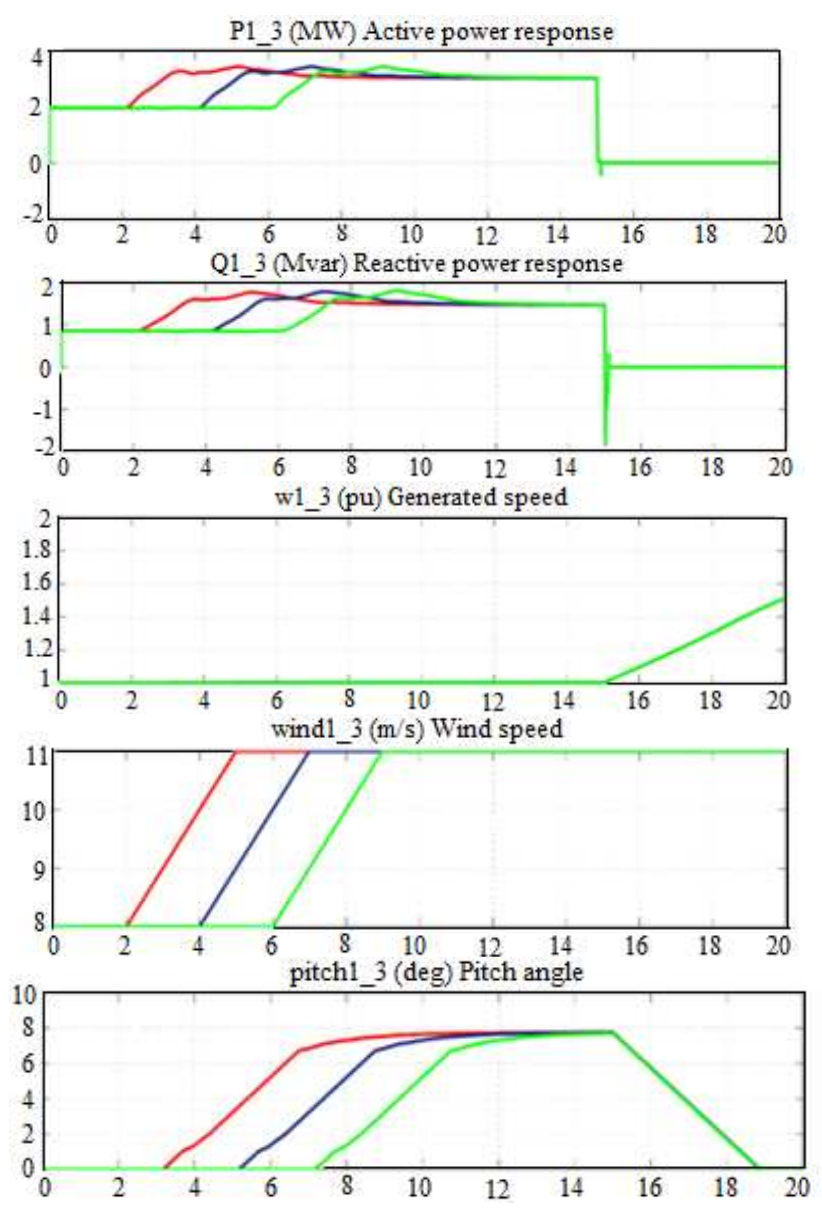

Fig. 9: Response of active, reactive power, generator speed, wind speed and pitch angle on wind turbine scope with STATCOM
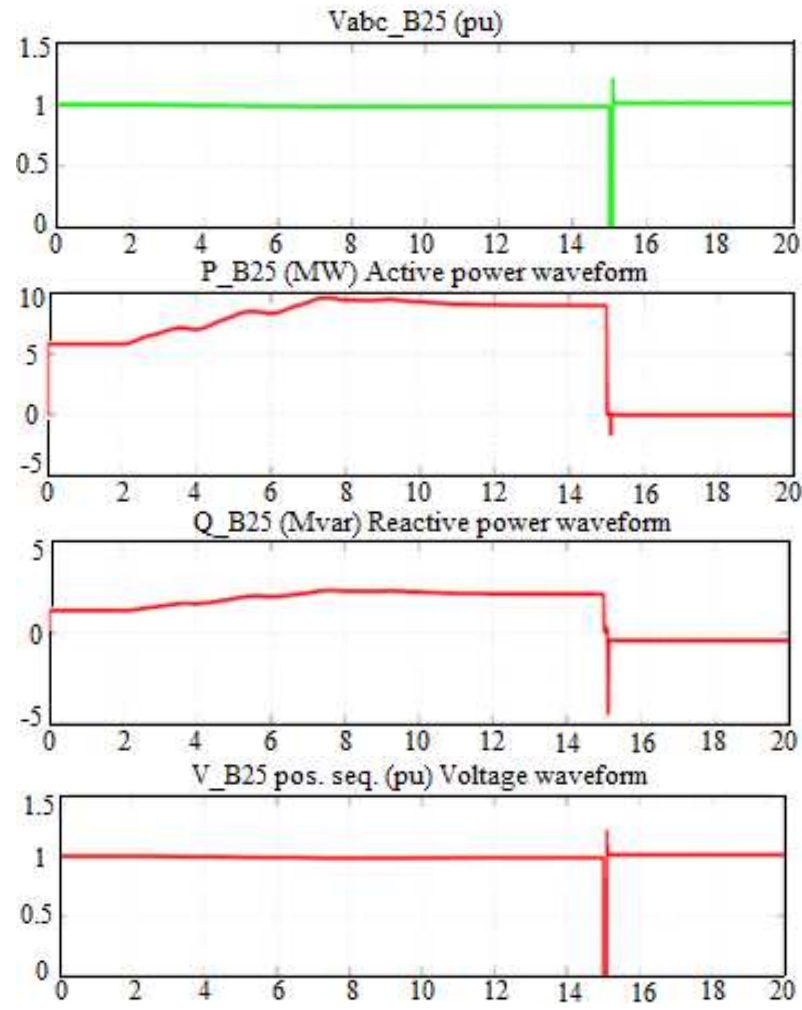

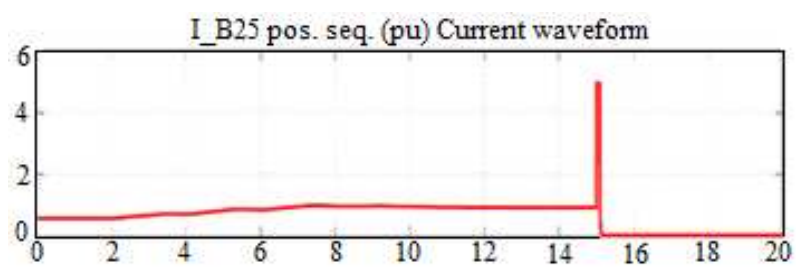

Fig. 10: Response of voltages, current, active and reactive power on the bus scope with STATCOM.

\section{Under three phase fault conditions}

The system is subjected to three phase fault at the grid and cleared after $88 \mathrm{msec}$ from $15 \mathrm{sec}$ to $15.088 \mathrm{sec}$, Without STATCOM the wind turbines will not be able to transfer all generated power leading to an acceleration of the wind turbines due to the imbalance between input mechanical power and output electrical power, and active power generated from the wind turbines to the grid without STATCOM is about zero MW. Wind turbines tripped at $15.1 \mathrm{sec}$ due to AC under voltage (positive sequence). When STATCOM is connected wind turbines enter in service and the active power generated become 8.664 MW. Thus, STATCOM has an important effect on the active power generated.

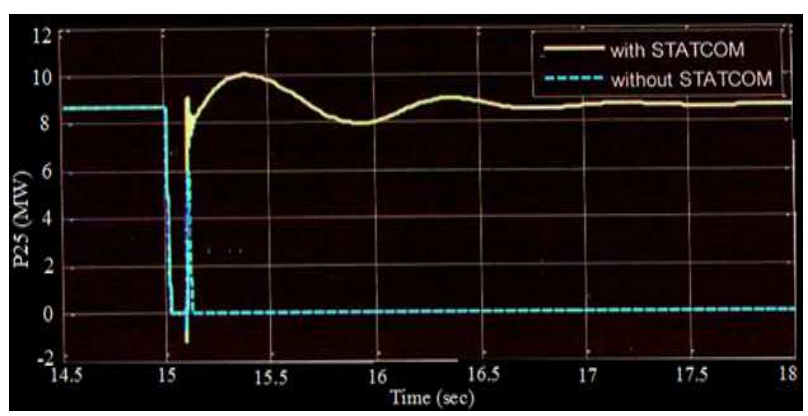

Fig. 20.1: Active power response of the system at bus-25

The STATCOM starts to absorb reactive power in order to help the system sustain the voltage variations. The reactive power without STATCOM was negative (-1273 MVAR) and the grid takes reactive power from capacitor banks of wind turbines. After using STATCOM, the reactive power becomes 1988 MVAR.

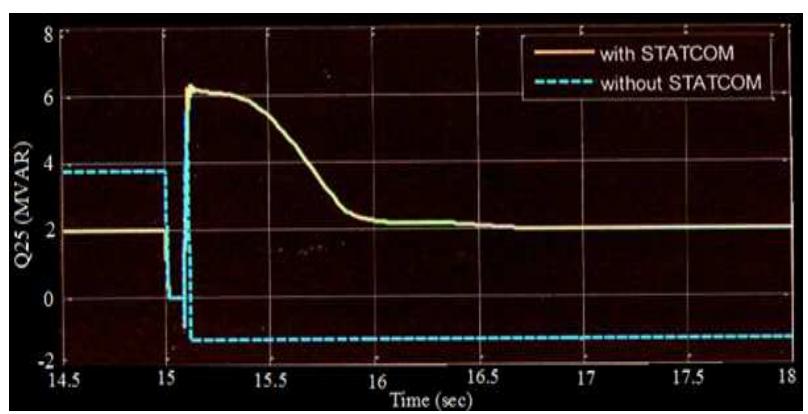

Fig. 20.2: Reactive power response of the system at bus-25

STATCOM improves the grid voltage, where the voltage at the grid without STATCOM was $1.024 \mathrm{Pu}$ and after using STATCOM becomes $0.985 \mathrm{Pu}$. 


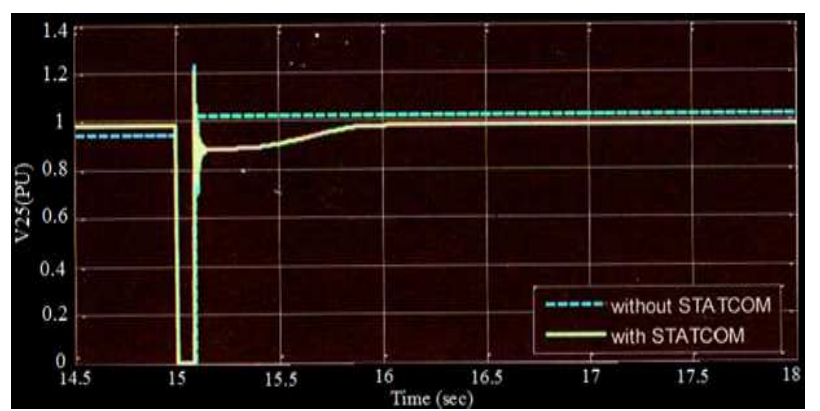

Fig. 20.3: Voltage response of the system at bus-25

During the period with a fault applied on the grid at bus25 at time $15 \mathrm{sec}$ with a time duration of $88 \mathrm{msec}$ of fault, all wind turbines are disconnected at time $15.1 \mathrm{sec}$ due to AC under voltage and no output power is generated due to the lost in the reactive power required during this fault where the power system and capacitor banks are not enough to supply the large amount of reactive power. This is a big problem for a large wind farms and the voltage of the grid increases due to the impact of the reactive power delivered from the capacitor bank. When a STATCOM is connected to the system, it supplies the required reactive power during a fault which is enough to keep the wind farm generating its rated power under a large time duration of high fault.

\section{Conclusions}

In this work, the wind farm power quality has been improved using FACTS devices such as STATCOM. The dynamic model of the power system has been built using MATLAB/Simulink software. The performance and the impact of STATCOM in static voltage stability margin enhancement has been studied in different fault scenarios. The main effect of STATCOM has been seen when a three-phase fault applied on the grid, as it is a dangerous fault during a long applied fault time duration on the grid. The transferred power and power factor has been improved by using STATCOM. The voltage of the grid is always constant, stable and close to the desired value (1 pu).

\section{Appendix: System parameters of STATCOM and wind turbine}

\section{Table 1: System Parameters of STATCOM}

Parameter

System Nominal Voltage

Value

System Frequency

Rating Power

$25 \mathrm{KV}$

$60 \mathrm{HZ}$

Capacitor

3 MVA

$1125 \mu \mathrm{F}$

Table 2: System Parameters of IG and wind turbine:
Parameter

Rating Power

Stator Voltage

Frequency

Stator Inductance

Rotor Resistance

Rotor Inductance
Stator Resistance
Magnetizing Inductance

$6.77 \mathrm{pu}$

Friction Factor

Pairs of Poles

Base wind speed

Maximum pitch angle

Pitch angle controller gain: [Kp Ki]

Nominal wind turbine mechanical output power

$5.04 \mathrm{~s}$

$0.01 \mathrm{pu}$

$3 \mathrm{p}$

$9 \mathrm{~m} / \mathrm{s}$

$45 \mathrm{deg}$

[5 25]

$3 \mathrm{MW}$
Inertia Constant

\section{References}

[1] T. Truong, K. Ro, "Improvement of LVRT characteristic of SCIG wind turbine system by incorporating PMSG," Int. J. Energy, Information and Communications, 3, 3, 2012.

[2] Q. Salem, I. Altawil, "Stability study of grid connected to multiple speed wind farms with and without FACTS Integration", Int. J. Electronics and Electrical Engineering 2, 3, 2014

[3] B. Pokharel, G. Wenzhong, "Mitigation of disturbances in DFIG based wind farm connected to weak distribution system using STATCOM", North American Power Symposium, 1-7, 2010.

[4] Q. Wei, G. Venayagamoorthy, R. Harley, "Real-time implementation of a STATCOM on a wind farm equipped with doubly fed induction generators industry applications", IEEE Transactions 45, 1, 98-107, 2009.

[5] C. Han, A. Huang, M. Baran, S. Bhattacharya, W. Litzenberger, L. Anderson, A. Johnson, A. Edris, "STATCOM impact study on the integration of a large wind farm into a weak loop power system," IEEE Trans on Energy Conversion, 23, 1, 226-233, 2008.

[6] M. Sheikh, M. Hossain, R. Hossain, "Stability enhancement of a grid connected wind farm by using STATCOM", Int. Conf. Electrical \& Electronic Engineering, Bangladesh, 2015.

[7] C. Li, R. Burgos, I. Cvetkovic, D. Boroyevich, "Active and Reactive Power Flow Analysis for STATCOM under Virtual Synchronous Machine Control," Workshop on Control and Modeling for Power Electronics, 2015.

[8] K. Pushpak, B. Kumar, A. Ravi, "Improving transient stability of wind farm using FACTS devices focused on STATCOM", Int. J. Engineering Applied Sciences and Technology, 1, 7, 163-167, 2016.

[9] C. Wessels, M. Molinas, "STATCOM control at wind farms with fixed-speed induction generators under asymmetrical grid faults", IEEE Transactions on Industrial Electronics, 60, 7, 2013.

[10] L. Chi, R. Burgos, I. Cvetkovic, D. Boroyevich, L. Mili, and P. Rodriguez, "Evaluation and control design of virtual synchronous- machine-based STATCOM for grids with high penetration of renewable energy", Energy Conversion Congress and Exposition, 5652-5658, 2014.

[11] G. Elsady, Y. Mobarak, A. Youssef, "STATCOM for improved dynamic performance of wind farms in power grid", Int. Middle East Power Systems Conference, Egypt, 2010, Paper ID 207.

[12] A. Salman, P. Hassan, R. Masoud, "Modeling and simulation of wind farm with STATCOM in MATLAB/Simulink environment", Bulletin Georgian National Academy of Sciences, 9, 2, 2015.

[13] F. Rong, S. Wanpeng, Y. Jian, J. Yapeng, "Study on application of STATCOM in voltage stability of wind farm incorporated system", Chinese control conference, 2013.

[14] Z. Saad, M. Lisboa, J. Kanayake, N. Jenkins, G. Strbac, "Application of STATCOMs to wind farms", IEEE proceedings on Generation, Transmission and Distribution, 145, 5, 2011. 